\title{
Foreword by the President of the International Phonetic Association
}

Since the 14th International Congress of Phonetic Sciences in San Francisco in August 1999, two decisive events have set signals for the future directions of phonetics in general and of the International Phonetic Association in particular. First of all, the Permanent Council for the Organization of International Congresses of Phonetic Sciences, the principal, quadrennial international forums for the presentation of phonetic research, and the Council of the International Phonetic Association, the oldest and most prominent scientific society of phonetics, separately voted in favour of a union, with the intention to affiliate the Permanent Council as a standing subcommittee to the IPA Council and to run future Congresses under the auspices of the IPA. This will broaden and intensify the activities of the IPA in all areas of Phonetic Science, even if the phonetic descriptions of languages will remain a traditional focus of attention. Secondly, a decision was taken by the IPA Executive to reach agreement for the Association's Journal to be published by Cambridge University Press. Upon the conclusion of the contract, we can now proudly present the first issue of volume 31 of the Journal of the International Phonetic Association under its new aegis. In conjunction, the two decisions taken by the IPA open up the prospect of a powerful international platform for the distribution of the state-of-the-art and new results in phonetic research.

In my inaugural address as incoming President of the IPA at the San Francisco Congress, I promised to follow the example of other scientific organizations in instituting workshops, under the sponsorship of the IPA, on significant topics in phonetics, and suggested, as one such 'hot' issue, phrase-level phonetics and phonology in unscripted communication. This idea was taken up at the Institute of Phonetics and Digital Speech Processing of Kiel University and led to the organization of an international symposium on 'Patterns of speech sounds in unscripted communication: production - perception - phonology', held at the conference centre Akademie Sankelmark, near Flensburg, Germany, from 8th to 11th Ocober, 2000, under the auspices of the IPA and with financial support from the German Research Council and the State Government of Schleswig-Holstein, whose contributions are gratefully acknowledged. A reviewed selection of the papers that were presented at the symposium are assembled in this first issue published by Cambridge University Press. It is hoped that this publication will trigger an increased interest in phrase-level phonetics and phonology in a great number and variety of languages and thus complement the WORD-PHONEMIC/ALLOPHONIC language illustrations, which have become a standard 
feature of the Journal, by more comprehensive PHONETIC ACCOUNTS OF COMMUNICATION in individual languages, on the one hand, and in human language in general.

The papers represent the principal subjects of the symposium,

- articulatory reduction and elaboration and their conditioning variables, and

- (dys)fluency and dialogue structure,

in a multilingual perspective of spontaneous speech. They combine symbolic descriptions with speech wave analyses and comprise some physiological/articulatory, in addition to the predominantly acoustic, accounts (Amelot et al.: nasal airflow, Nicolaidis: electropalatography). With one exception (Duez), they are productionoriented. To model the largely successful decoding of highly 'distorted' speech by listeners in communicative settings we lack, at present, an appropriate psycholinguistic research paradigm that transcends the strictly linear segmental phonemic approach, which is usually applied in perception testing. As regards the phonological perspective, the dominant view in these papers is the one that relates processes to canonical forms, but there are also declarative approaches (Wesener, Simpson, Lennes et al., Ogden), and all the papers focus on componential features besides segments to a greater or lesser degree.

The sequence of the papers is by subject matter in the first instance, those dealing with dialogue structure and dysfluency (Ogden, Shriberg) following the ones on patternings of sounds at the phrase-level. The paper by Lennes et al. marks the transition between the two areas in that it topicalizes both. Secondly, the over-all arrangement is by language, starting with German (Kohler, Wesener, Simpson), for which the largest structured annotated data bank and the most comprehensive data of phrase-level sound-patterns are available, followed by Suffolk English (Simpson), Swedish (Engstrand \& Krull), a comparative study of Slavic languages - Bulgarian, Czech, Polish, Russian - as well as Italian and Greek (Barry \& Andreeva), followed in turn by Greek (Nicolaidis), French (Basset et al., Duez), Hindi (M. Ohala), Finnish (Lennes et. al., Ogden), and finally by (dysfluency in) American English (Shriberg).

None of the papers can offer exhaustive accounts of phrase-level phenomena in the respective languages. Some are more oriented towards the presentation and discussion of individual examples, even to the extent of becoming anecdotal, whereas others attempt to show up general trends, even across languages, sometimes perhaps on too scanty material. But they all converge in a realization of the need for more intensive research into patterns of speech sounds in unscripted communication.

Klaus J. Kohler 